Review of Cyril Hédoin's L'institutionnalisme historique et la relation entre théorie et histoire en économie [Historical institutionalism and the relation between theory and history in economics]. Paris: Classiques Garnier, 2013, 435 pp.

\title{
LAURE BAZZOLI
}

Université Lyon 2

This book originates from Cyril Hédoin's doctoral work on institutionalism in economic thought. It supplies extensive knowledge on the founding figures of institutional economics (Gustav von Schmoller, Max Weber, Thorstein Veblen, John R. Commons, and Karl Polanyi), which makes it a potential textbook on the subject, and it provides a detailed analysis of what defines an "authentically institutionalist approach" to economics (p. 9). Because economists can say "we're all Institutionalists now" (p. 7, emphasis in the original), the author reflects on the identity of what he and other French economists call historical institutionalism - a research programme that is distinct from (and critical of) mainstream economics and its method of analysing institutions. The adjective 'historical' not only refers to an approach that emphasizes the history of economic thought, but also suggests the specific criterion of demarcation used by Hédoin to identify the essence of this heterodox institutionalism. This approach recognizes the importance of the historicity of social phenomena and of social knowledge, and therefore investigates the relation between theory and history. This book also contributes to the history of ideas, the philosophy of economics, and the economics of institutions.

By using two categories of Imre Lakatos's methodology of science, Hédoin proposes a rational reconstruction of the thought of Schmoller, Weber, Veblen, Commons, and Polanyi in order to delineate the hard core of the research programme of historical institutionalism. The choice to concentrate on these five authors (thus avoiding the reduction of historical institutionalism to American institutionalism) is based on their importance for this research programme: they are representative of its identity and offer significant insights that relate theory and history which, for the main part, are convergent and often complementary. Hédoin interprets these authors by analysing the logical 
connection between theory and history: specifically, this refers to the epistemological issue of historicization of theory (i.e., the method of social knowledge) and the substantive issue of theorization of history (i.e., the explanation of historical dynamics). The book is structured according to these mirror issues in order to analyse the primary methodological and theoretical principles that characterize historical institutionalism.

Part one of the book develops what Hédoin identifies as the three principles underlying the historicization of theory: (1) consideration and treatment of the problem of historical specificity (this addresses the tension between the general and the particular); (2) adoption of methodological institutionalism (this addresses the tension between action and structure); and (3) appeal to abduction and ideal types as methods of knowledge (this addresses the tension between concept and reality). Hédoin begins with an exploration of the philosophical foundations of these principles which have their basis, according to him, in German neo-Kantian philosophy (Wilhelm Dilthey, Heinrich Rickert) and American pragmatist philosophy (Charles Sanders Peirce, John Dewey). Although there are differences between these philosophical traditions, they share a common emphasis on the historicity of science, which opposes the positivist epistemology that has dominated economics. Neo-Kantianism is, Hédoin states, the first philosophy to deal with the relation between theory and history; it addresses the specificity of the cultural sciences and aims to establish their scientific legitimacy. Pragmatism makes a "decisive contribution" (p. 63) by articulating connections between its theory of knowledge and its theory of action; these connections underlie all three principles for historicizing theory, especially in the social sciences. These philosophical positions legitimize the historical institutionalist research programme whose main characteristics are to recognize the historical specificity of social phenomena (that is, the uniqueness of historical events), and, consequently, to stress that social sciences are not nomological sciences, that they rather produce theories that are contextual means of understanding a global historical process.

Part one of the book continues with a study of how the German historical school (under Schmoller and Weber) and the American institutional school (under Veblen, Commons and, by extension, Polanyi) have developed these principles of the social sciences. Each author is scrutinized in order to identify his contributions and his weaknesses 
concerning the historicization of theory (Commons is regarded as having originally married the two philosophical foundations of institutionalism). In so doing, Hédoin demonstrates both the differences and commonalities among these authors. He argues that their epistemological contributions converge in a historical conception of knowledge and theory, which deals with the tension between the general and the particular. This conception identifies the scientific character of the social sciences by taking into account their specificities. For the authors examined, these specificities pertain to the absence of natural laws and to the role of values in studying social facts and human phenomena.

Part two of the book develops what Hédoin identifies as the three principles underlying the theorization of history: (1) a substantive conception of the subject-matter of economics; (2) an evolutionary approach to institutions; (3) and the concept of capitalism as a historical system specific to Western economies. This part begins with a critical evaluation of how Schmoller, Weber, Commons, and Polanyi analyse the substantive dimension of economics. Borrowing from Polanyi (pp. 174-178), Hédoin defines substantive economics in opposition to the formal meaning of 'economic' in terms of maximizing rationality. In contrast, the substantive economy is "the set of institutions aiming at allowing individuals to fulfil their needs" (p. 19). The study of the economy in this sense requires the continuous articulation of actions and institutions (methodological institutionalism).

For Hédoin, Schmoller developed the first systematic study of institutions (though his contribution is often overlooked); but it is Commons' theory that completely satisfies the principle of substantive economics. Additionally, the contributions of Weber and Polanyi are very important, but the author indicates that their variants of methodological institutionalism are incomplete: Weber considers institutions to be essentially constraints on actions, whereas Polanyi fails to develop a theory of action-this, in part, explains the ambiguity surrounding his notion of "embeddedness" as discussed by Hédoin (pp. 255-256). Furthermore, their analyses (especially Polanyi's) are not evolutionary. It is for this reason that the author focuses on the contributions of Veblen and Commons when investigating the second principle of the theorization of history-this pertains to the evolutionary approach to institutions. Building on the work of Geoffrey Hodgson, Hédoin analyses the ontological and methodological lessons 
derived from the Darwinian revolution, before examining the contributions of Veblen and Commons. He maintains that historical institutionalism should combine Veblen's analysis in terms of natural selection and Commons's analysis in terms of artificial selection. Hédoin argues that these two types of evolutionary processes refer to two dimensions and two timescales of social evolution, and that natural selection includes cultural selection from a Darwinian ontological point of view.

Part two of the book concludes with a discussion of the essential object of study for all the authors considered: capitalism as a contingent historical system produced by a non-teleological evolutionary process. According to Hédoin, these authors develop a theorization of history in order to understand the process of emergence of capitalism, and each author focuses on different aspects of this process. Hédoin brings together Veblen and Weber because they both (although differently) analyse this process as part of a more general process of institutional rationalization of the Western world. He also draws connections between Commons and Polanyi because they both stress the social construction of the institutional foundations of capitalism, which is characterized by the generalization of market processes. Through specific systems of concepts, their contributions converge, argues Hédoin, in the understanding of the historical dynamics of Western capitalism as an empowerment of the economic order that brings tensions in the human world.

This book offers a very clear, comprehensive and stimulating analysis of the theories of the founding figures of historical institutionalism. By comparison with the existing literature on heterodox institutionalism, it has two specific merits. The first is that it integrates both the German and the American foundations of historical institutionalism; it builds many dialogues and relevant links between the authors examined without neglecting their differences and weaknesses. The second merit lies in its detailed analysis of the relation between theory and history. Indeed, the choice to focus on this relation to delineate this research programme directs one's attention to its main characteristics: its epistemological and methodological claims about the process of theorization in the social sciences, and further, its substantive and theoretical claims about the analysis of the evolution of our modern economic system. However, I want to highlight two limitations of this erudite book. 
First, because of its thorough presentation of the work of five 'big authors', the book has little room to question the present status and stake of this research programme. The concluding chapter broaches the discussion of this subject by listing some research in economics that can be included in this tradition (e.g., French theories of regulation and conventions, and the work of Masahiko Aoki and Douglass C. North). Given the ongoing transformations of mainstream economics, Hédoin endorses an avenue of research that consists in combining historical institutional economics with modern techniques of modelling; this is such that the combination does not reduce the preoccupation for historical specificity and all its methodological implications. I agree with Hédoin that the (relative) decline of positivism in economics, along with the resurgence of pragmatism in philosophy, create opportunities for development in historical institutionalism today. I also agree that this development could definitively break from the now obsolete Methodenstreit. But I maintain-in accordance with an authentic institutionalist approach-that the conditions for a balanced mix between historicization and formalization must be properly identified. Crucially, it must be stated that historical institutional economics encompasses formalized institutional economics given it deals with social complexity in historical dynamics. Furthermore, the issue of the type of formalization consistent with methodological institutionalism and its evolutionary content must be clarified. Finally, this discussion cannot escape inquiring what should be rightly considered 'empirical' in economics - this is an issue that has always been a point of divergence between historical institutionalism and mainstream economics.

The second issue, in connection to this last remark, is not so much a criticism than it is an extension of the author's study of historical institutionalism. Through Hédoin's analysis of the methodological positions of Weber and Commons, one can sense a tension between the (epistemological) nominalism of the neo-Kantian tradition and the (ontological) realism of the pragmatist tradition. If both traditions state that concepts are not a 'copy of reality', pragmatism defends a mediated link between concepts and reality and is therefore pressed with the issue of the validity of theories in reality-that is, in social life and ordinary experience. Here the connection between knowledge and action-science and praxis-becomes essential and distinctive for historical institutionalism. Dewey and Commons have best shown that social theories and philosophies have to be tested in action, that is, 
according to their empirical consequences; this is especially so for implementations of public policy and institutional design which are regarded as experimentations for the social sciences. From this perspective, history is crucial not only as 'past' (i.e., as it concerns the study of the specific historical path for understanding the present state of a system) but also as 'future' (i.e., as it concerns experimentation of specific institutional policies to test the changes deemed necessary). Thus, when one takes into account the relation between theory and reality, the normative and practical consequences of theories become a critical part of the research programme of historical institutionalism. On this point, although all the authors here considered relate economics, politics and ethics, there remain significant differences between them. On the one side, Schmoller, Commons, and Polanyi explicitly applied economic analysis to social reform and were engaged in issues concerning democracy and social control over the economy. On the other side, Weber and Veblen stressed the issue of objectivity in the social sciences and were somehow reluctant to apply science to policy. Surely, an adequate discussion of the positions of the authors with respect to this issue would have been lengthy - that might be the reason why Hédoin left it out. But this issue of the relations between positive and normative judgments, and between theory and practice, is highly relevant when the goal is to characterize historical institutionalism within economics. In any case, it sheds light on the institutionalist conception of the specificities and the stakes of the historical sciences.

In this book, Cyril Hédoin investigates the founding fathers of institutionalism with the aim of analysing the specific principles that distinguish this research programme. The originality of this book lies in its attempt to identify a single criterion of demarcation that could be both epistemological and substantive: the institutionalist's attention to the relation between theory and history. One might argue that this criterion is not the only marker of the identity of heterodox institutionalism; but surely it is the most structuring and the most consensual one. Hédoin's book demonstrates this point very convincingly.

Laure Bazzoli is associate professor of economics at the University of Lyon (Lyon 2) and member of TRIANGLE, a French interdisciplinary research unit (whose themes are: action, discourse, political and economic 
thought). She has specialized on the thought of the institutional economist J. R. Commons and of the pragmatist philosopher J. Dewey. Contact e-mail: <laure.bazzoli@univ-lyon2.fr> 